\title{
The Frequency of CYP2C9 and VKORC1 Gene Polymorphic Alleles in Georgian Population
}

\author{
Kakauridze $\mathrm{N}^{1}$, Jochadze $\mathrm{T}^{2}$, Gaiozishvili $\mathrm{M}^{2}$, Buadze $\mathrm{T}^{2}$, Nikolaishili $\mathrm{G}^{3}$, Baratashvili $\mathrm{N}^{2}$, and \\ Lezhava $\mathrm{T}^{2}$.
}

\begin{abstract}
Cardiovascular diseases (CVD) remain the biggest cause of deaths worldwide. More than 17 million people died from CVDs in 2008 [1]. In the structure of CVD, coronary heart disease (CHD) and stroke are the top causes of death $(47,7 \%$ and $16,4 \%$ respectively) [2].

CVD are complex disorders that include dysfunctional conditions of the heart, arteries and veins?. Within these diseases, thrombosis (myocardial infarction, insult arterial and deep vein thromboses) is the third most common CVD worldwide. It can derive from: genetic factors and acquired changes in the clotting mechanism $[3,4]$.

Warfarin is one of the most widely used anticoagulant drug, which requires a thorough risk-benefit analysis since the dose prescribed should avoid hemorrhagic complications and achieves suppression of thrombosis. Warfarin pharmacogenetic studies demonstrated that variants in the CYP2C9 (Cytochrome P450 2C9) and VKORC1 (Vitamin K epoxide reductase complex subunit 1) genes account for approximately 50-60\% of drug dosing variability. Cytochrome P450 2C9 is the major enzyme responsible for metabolising the active $\mathrm{S}$ enantiomer. Although of CYP2C9 gene is shown 6 different mutations, the most studied CYP2C9 alleles include CYP2C9*1 (wild-type), and the partially functional CYP2C9*2and CYP2C9*3 variants. These last two are associated with decreased metabolic efficiency of the CYP2C9 enzyme and increased risk of bleeding when administrated initial dosages of warfarin $[5,6]$. The epidemiological studies indicated, variability of the frequency of CYP2C9 gene polymorphism in American population is approximately $29 \%$ and in African-American population - 3.6\% [7]). Recent data indicated that Caucasians are distinguished of high frequency by distribution of polymorphic alels in comparison with the African, Asian and Japanese population [8,9,10,11].

Half of patients who need the anticoagulant therapy don't receive it for prevention of complication. The experience of using of genetic test for establish of warfarin dose stability shown the reduction of bleeding complication $(2,3,8)$.

From this viewpoint, it is important to study to determine the frequency of CYP2C9 and VKORC1 gene polymorphic alleles in population from different regions of Georgia: Eastern Georgia and Western Georgia for Warfarin dose regulation perspectives in CVD events patients.
\end{abstract}

Keywords-CYP2C9, VKORC1, warfarin, SmartAmp-2®.

\section{MATERIALS AND METHODS}

$\mathrm{T}$ HE histories of each person include information about: age, body mass index, sex, harmful habits, the existing previous myocardial infarction, insults, arterial and venous thrombosis (thrombosis states), warfarin treatment uses, doses

\footnotetext{
1 Tbilisi State Medical University; ${ }^{2}$ Ivane Javakhishvili Tbilisi State
} University, Tbilisi, ${ }^{3}$ Batumi Central Hospital, Georgia. of warfarin and indications, genetical disposition of thrombosis (by interrogation) were obtained.

For determination of the frequency of CYP2C9 and VKORC1 genes polymorphism we investigated in blood totally 150 persons from Eastern Georgia (Kakheti region) and Western Georgia (Samegrelo region), among them: 50 healthy individuals, 50 patients with cardiovascular disease and 50 patients with cardiovascular events (CVE), who takes warfarin without genetical investigations (the clinical characteristic of patents is done on the table 1)

For genetical investigation we used a rapid detection system of genetic polymorphisms, the Smart Amplification Process version 2 (SmartAmp-2® or SMAP2), which enables genotyping under isothermal temperature regime using small amount of blood.

The SMAP 2 assay was carried out in a $25-\mu \mathrm{L}$ reaction mixture containing $3.2 \mu \mathrm{mol} / \mathrm{L}$ folding primer, $3.2 \mu \mathrm{mol} / \mathrm{L}$ turn-back primer, $1.6 \mu \mathrm{mol} / \mathrm{L}$ boost primer, $0.4 \mu \mathrm{mol} / \mathrm{L}$ of each outer primer, $16 \mu \mathrm{mol} / \mathrm{L}$ competitive probe (in the case of CYP2C9*2), $1.4 \mu \mathrm{mol} / \mathrm{L}$ of each deoxynucleoside triphosphate (dNTP), $50 \mathrm{~mL} / \mathrm{L}$ DMSO, $20 \mathrm{mmol} / \mathrm{L}$ Tris- $\mathrm{HCl}$ (pH 8.0), $10 \mathrm{mmol} / \mathrm{L} \mathrm{KCl}, 10 \mathrm{mmol} / \mathrm{L}(\mathrm{NH} 4) 2 \mathrm{SO} 4,8 \mathrm{mmol} / \mathrm{L}$ MgSO4, $1 \mathrm{~mL} / \mathrm{L}$ Tween ${ }^{2}$ 20, SYBR® Green I (Molecular Probes) diluted to 1 part in $100000,6 \mathrm{U}$ Bst DNA polymerase.

The templates used for the assays were prepared by mixing 1 volume of whole blood with 2 volumes of $150 \mathrm{mmol} / \mathrm{L}$ $\mathrm{NaOH}$, vortex-mixing, and incubating at $98{ }^{\circ} \mathrm{C}$ for $5 \mathrm{~min}$. The sample preparation was chilled on ice, and $1 \mu \mathrm{L}$ was added directly into a reaction mixture. SMAP 2 reactions were assembled on ice and incubated at $60{ }^{\circ} \mathrm{C}$ for $60 \mathrm{~min}$. The Esequant tube scanner system (QIAGEN) was used to maintain isothermal conditions and to monitor the fluorescence.

Statistical analysis: Baseline demographics were analyzed using descriptive statistics. Numerical variables were represented as mean \pm standard deviation Categorical variables were presented as percentages. Differences between controls and patients for genetic damage indices were analyzed by the Student's t-test.P value of less than 0.05 was considered significant. 
TABLE

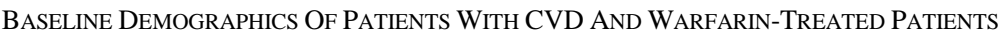

\begin{tabular}{|c|c|c|c|}
\hline $\begin{array}{c}\text { Pts with CVD } \\
\text { Total N (100) }\end{array}$ & Pts with CVD (50) & Pts with CVE +warfarin (50) & Healthy donors Total N (50) \\
\hline $\begin{array}{c}\text { Age (years) } \\
\text { M } \pm \text { SD }\end{array}$ & $58,4 \pm 14,6$ & $53,7 \pm 12,8$ & $27,3 \pm 7,4$ \\
\hline Male & $57 \%$ & $54 \%$ & $51 \%$ \\
\hline Female & $43 \%$ & $46 \%$ & \\
\hline Atrial fibrillation & $9(18 \%)$ & $49 \%$ & \\
\hline Mitral valve replacement & & $7(14 \%)$ & \\
\hline Deep vein thrombosis & & $11(22,5 \%)$ & \\
\hline Cerebrovascular accident & $8(16 \%)$ & $78 \%$ & \\
\hline Myocardial Infarction & $74 \%$ & $4(0,8 \%)$ & \\
\hline Aortic valve replacement & $2(0,4 \%)$ & & \\
\hline $\begin{array}{c}\text { Most common } \\
\text { concomitant diseaseand } \\
\text { risk-factors }\end{array}$ & & $46(92 \%)$ & \\
\hline Hypertension & $44(88 \%)$ & $14(28 \%)$ & \\
\hline Diabetes & $8(16 \%)$ & $28(56 \%)$ & \\
\hline Hyperlipidemia & $34(68 \%$ & & \\
\hline Other anticoagulants & & $42(84 \%)$ & \\
\hline Aspirin & $6(12 \%)$ & & \\
\hline Clopidrogrel & $8(6 \%)$ & & \\
\hline INR range1.5-2.0 & & & \\
\hline
\end{tabular}

\section{RESULTS AND DISCUSSION}

The methodological News, which is presented by us, (detection of mutations and introduction of single and sensitive tests for SNP ( single nucleotide polymorphism- genotyping) will allow first determine the frequency of CYP2C9 and VKORC1 genes polymorphism in the Georgian population, that has the theoretical and a great practical significance for prevention and treatment of Thrombosis.

In the Eastern region population of Georgiain determining the CYP2C9 gene polymorphism, the results of the analysis revealed that healthy individuals with the homozygous wildtype genotypes amounted to $75 \%$, the number of heterozygous was $25 \%$ and individuals with mutant genotype were not fixed in the group investigated by us (Fig 1).

In determining the VKORC1 gene polymorphism, the results of the analysis revealed that healthy individuals with the homozygous wild-type genotypes amounted to $42 \%$, the number of heterozygous was $39 \%$ and homozygous mutant $19 \%$.

There were genetical investigation results significant differences between the patients (with CVD events) groups (both groups: patients without warfarin treatment and patients, who received warfarin without genetic investigations), but we revealed some regional differences in received results.

In Eastern Georgian patients with cardiovascular events the results obtained by determination CYP2C9 gene polymorphism appears that the number of individuals with homozygous wild-type genotype was $20 \%$, heterozygous $50 \%$ and homozygous mutant - 30\% (Fig 2)
In the results obtained by determination VKORC1 gene polymorphism in Eastern Georgian population we established that the number of individuals with homozygous wild-type genotype was $55 \%$, heterozygous - $35 \%$ and individuals with homozygous mutant genotype were $10 \%$.

The results obtained by investigation of people from Eastern region, differ from the data of population of Western regions of Georgia.

In the Western Georgian population the wild-type homozygotes by the gene VKORC1 were - 90\%; heterozygotes - 10\%; mutant homozygotes have not met at all. In Patients with CV events fromWesten Georgia, wild-tipe homozygotes and heterozygotes by CYP2C 9 gene were almost the same rate $(51 \%$ and $49 \%$-, respectively); mutant homozygotes were not revealed.

The ratio of the frequencies of CYP2C9 gene alleles in healthy donors from Eastern and Western Georgia are different. In Western region healthy population - wild-type homozygotes - 77\%; heterozygotes - $23 \%$ were revealed; mutant homozygotes were not met. The contribution of CYP2C9 to variability in Georgian population was similar to that observed in Caucasians, while the contribution of VKORCl to variable dose was much lower than in Caucasians, and more similar to what has been observed in AfricanAmericans [13].

As is showed in our materials there exist the significant regional differences in healthy Eastern population VKORC1 frequency are elevated in comparison of the same groups VKORC1 frequency from Western Georgia, but the CYP2C9 genes polymorphisms are the same in the healthy population groups. These data underline that polymorphism frequencies are not similar among different region population of Georgia. The regional differences may be explained by historical events of Georgia (numerous expansion by the different 
occupants of the Eastern and western Georgia) as habits peculiarities.

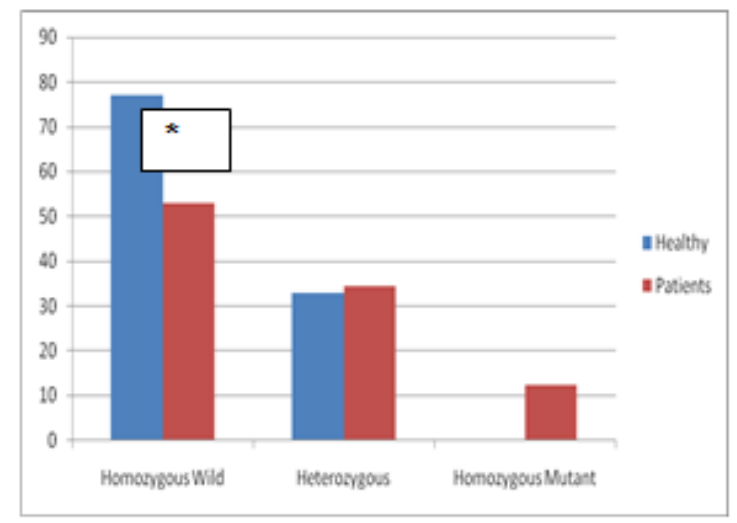

Fig 1.CYP2C9 gene polymorphism in Eastern

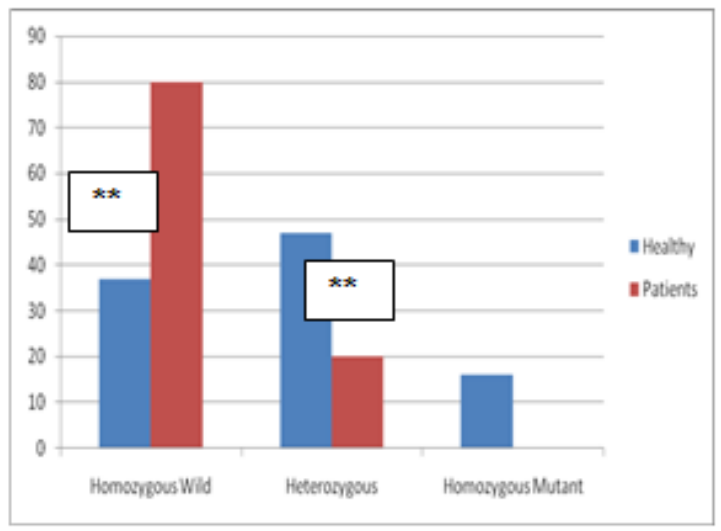

Fig 2.VKORC1 gene polymorphism in Eastern Georgian population $\left({ }^{*} \mathrm{P}<0.01 ;{ }^{*}{ }^{*}<0.001\right)$

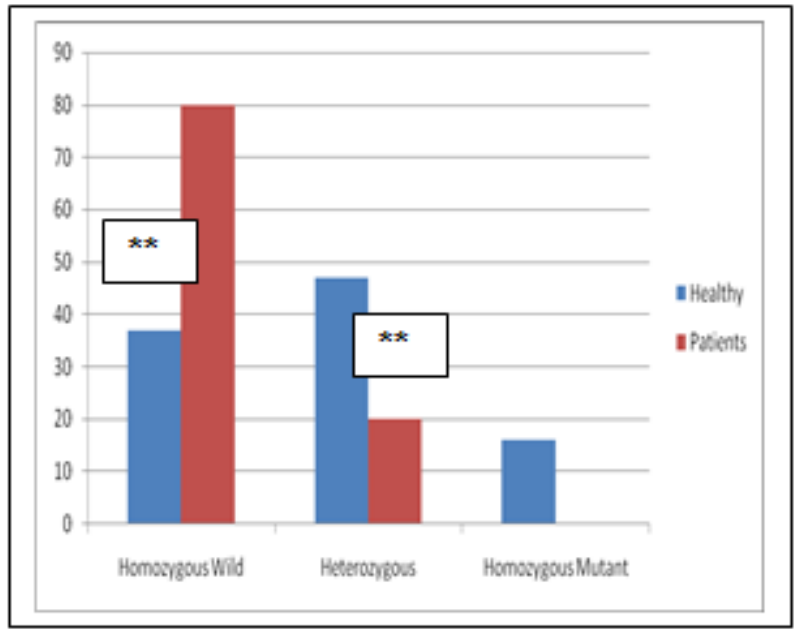

Fig.3.YP2C9 gene polymorphism in Western



Fig.4. VKORC1 gene polymorphism in Western

Georgian population $\left({ }^{*} \mathrm{P}<0.01 ;{ }^{*}<0.001\right)$

It's interesting VKORC1 homozygote form frequency statistically elevates in CVD patients in comparison of the healthy groups as in Eastern as well in Western population. We suggest that mentioned relation between CVD and VKORC1 homozygote forms have the environmental factors and the other genes influences [14]. This fact require further complex investigations of dyslipidemia, clotting factors, Apo E gene [15] and etc.

VKORC1 single nucleotide polymorphisms (SNPs) explain a large fraction of the interindividual variation in warfarin dose, and VKORC1 has an approximately three-fold CYP2C9 effect.The time to achieve stability is mainly associated with the CYP2C9 genotype. Warfarin resistance has been related to several missense mutations in the VKORC1. Algorithms incorporating genetic (CYP2C9 and VKORC1), demographic, and clinical factors to estimate warfarin dosage could potentially minimize the risk of overdose during warfarin induction [6].

Thus, VKORC1 and / or CYP2C9 genes polymorphisms are presented in a number of clinical dosing algorithms and in prospective clinical trials. It is revealed the significant variation of genotypes in patients with CVD (in both studied regions in Georgian population), which indicates the importance of as in treatment process, as well as for the prevention of thrombosis.

\section{REFERENCES}

[1] WHO, WHF, WSO. Global Atlas on cardiovascular disease prevention and control, 2011

[2] Mozaffarian D et al.Heart Disease and Stroke Statistics-2015.UpdateA Report From the American Heart AssociationCirculation. 2015;131:e29-e322

[3] Menon J, Salman MM, Md GH: Venous thrombolysis: Current perspectives. Curr Treat Options Cardiovasc.Medl.2004; 6:159-168.

[4] Khan S, Dickerman JD.Hereditary thrombophilia.Thromb J.2006; 4:117.

http://dx.doi.org/10.1186/1477-9560-4-1

[5] Rettie AE, Tai G: The pharmacogenomics of warfarin. MolInterv. 2006; 6:223-227 http://dx.doi.org/10.1124/mi.6.4.8

[6] Nada Božina. The pharmacogenetics of warfarin in cinical practice.BiochemiaMedica. 2010;20:33-44.

[7] Schwarz Ui, Ritchie MD, bradford $\mathrm{Y}$ et al. Genetic determinants of response to warfarin during initial anticoagulation. N Engl J Med. 2008; 358: 999-1008.

http://dx.doi.org/10.1056/NEJMoa0708078 
[8] Moyer TP, O'Kane DJ, Baudhuin LM, et al. Warfarin sensitivity genotyping: a review of the literature and summary of patient experience. Mayo Clin Proc. 2009; 84: 1079-1094. http://dx.doi.org/10.4065/mcp.2009.0278

[9] Jukic I, et al. ABO Blood Groups and Genetic Risk Factors for Thrombosis in Croatian Population. Croatian Medical Journal. 2009; 50(60): 550-558. http://dx.doi.org/10.3325/cmj.2009.50.550

[10] Saour J, Shereen A, Saour B, Mammo L. CYP2C9 polymorphism studies in the Saudi population. saudi medical Journal, 2011; 23 (4): 347-352.

[11] Wadelius M, Pirmohamed M. Pharmacogenetics of warfarin: current status and future challenges. Pharmacogenomics J, 2007;7: 99-111. http://dx.doi.org/10.1038/sj.tpj.6500417

[12] Sanderson S, Emery J, Higgins J. CYP2C9 gene variants, drug dose, and bleeding risk in warfarin-treated patients: a HuGEnet systematic review and meta-analysis. Genet Med., 2005; 7:97-104. http://dx.doi.org/10.1097/01.GIM.0000153664.65759.CF

[13] Cavallari LH, Langaee TY, Momary KM, Shapiro NL, Nutescu EA, Coty WA, et al. Genetic and clinical predictors of warfarin dose requirements in African Americans. ClinPharmacolTher. 2010;87:459464.

http://dx.doi.org/10.1038/clpt.2009.223

[14] Shahin M. H. et al. Genetic and nongenetic factors associated with warfarin dose requirements in Egyptian patients. Pharmacogenet Genomics. 2011; 21: 130-135. http://dx.doi.org/10.1097/FPC.0b013e3283436b86

[15] Kimmel S.E et al. Apolipoprotein E genotype and warfarin dosing among Caucasians and African Americans.The Pharmacogenomics Journal. 2008; 8 : 53-60. http://dx.doi.org/10.1038/sj.tpj.6500445 